\title{
Cell Abnormality in Pap Smear in Women with Postmenopausal Bleeding
}

\author{
GHADA AHMED ASKAR, FATMA EL ZAHRAA SALAH EL DEEN SAFE EL DEEN, \\ HAZEM MOHAMMED MOHAMMED ABD EL GAFFAR, EMAN MUHAMMAD \\ SALAH EL DEEN.
}

\begin{abstract}
Cancer cervix is a preventable and curable disease due to effective screening methods. Uterine cervix is ideal for screening due to easy accessibility for inspection, palpation and exfoliative cytology. The Pap smear is a screening test for cervical cancer, and with appropriate follow-up it can reduce cervical cancer incidence by up to $\mathbf{8 0 \%}$. This study includes fifty peri and postmenopausal women, cervical smears were taken in the Out-patient Clinic of Gynecology and Obestetrics Department and Pap stain was used for each sample, and the criteria of Bethesda (2014) was used for the diagnosis of each case. Bleeding was the main complaint in $\mathbf{9 2 \%}$ patient and the remaining $\mathbf{8 \%}$ complained from vaginal discharge and itching. Thirty nine patients were negative for intraepithelial lesion or malignancy (non-neoplastic), eight showed neoplastic changes, and $\mathbf{3}$ samples were insufficient for cytological interpretation. Two out of the $\mathbf{8}$ cases showed neoplastic lesions were atypical squamous cells of undetermined significance (ASCUS), two diagnosed as atypical squamous cells cannot exclude HSIL (ASC-H), 3 were high grade squamous intraepithelial lesions (HSIL) and one cases had features of squamous cell carcinoma (SCC). Six out of 39 samples showed only pure atrophy, three showed follicular cervicitis, three had features suggestive of Tichomonas vaginalis infection, one diagnosed as HSV infection, one showed bacterial vaginosis and eleven cases showed nonspecific inflammation. Non-neoplastic cases included also six cases showed metaplastic changes and eight had normal cytological findings. Conclusion: cervical smears is important in early detection of cervical carcinoma and its precursors in Sohag community as an easy, costless, accessible, and reliable manner and Bethesda system (2014) is beneficial for accurate diagnosis.
\end{abstract}

\section{Introduction}

Cancer of the uterine cervix is the fourth most common cancer worldwide in females, and the seventh most common cancer overall (Ferlay et al., 2013). In Egypt cervical cancer ranks as the $13^{\text {th }}$ most frequent cancer among women and the $10^{\text {th }}$ most frequent cancer among women between 15 and 44 years of age (ICO Information Centre on HPV and Cancer, 2016). It is an important cause of morbidity and mortality among women worldwide and a major public health problem (Collaço and Zardo, 2008).

So we do Pap smear for complaining women to highlight the importance of using cervical smear in detection of cervical carcinoma and its precursors in Sohag community and to clarify the importance of using Besthesda system (2014).

Cancer cervix is a preventable and curable disease due to effective screening methods. Uterine cervix is ideal for screening due to easy accessibility of the cervix for inspection, palpation and exfoliative cytology (Gupta et al., 2013).

The Pap smear is a screening test for cervical cancer, and with appropriate follow-up it can reduce cervical cancer incidence by up to $\mathbf{8 0 \%}$ (Arbyn et al., 2010). 
If the Pap smear result is positive because of an infection, the underlying cause should be treated. The test should then be repeated in $\mathbf{2 - 3}$ months, because cancer of the cervix can be hidden by an infection. Persistent inflammation leads to increased cellular turnover, especially in the epithelium, and results in the emergence of cells that are at a high risk for malignant transformation (Moss et al., 2005).

Not getting regular screening, lack of appropriate follow up of suspicious cases, may lead to failure of prevention of cancer cervix (DeMay, 2007).

This study clarifies the importance of using cervical smears in detection of cervical carcinoma and its precursors in Sohag community as an easy, costless, accessible, and reliable manner in the Out-patient Clinic of Gynecology and Obstetrics Department and to clarify the usefulness of Bethhesda system (2014) for accurate diagnosis.

\section{Patient and method}

The cervical smears were taken in the Out-patient Clinic of Gynecology and Obstetrics Department and the material was prepared and stained in the Cytology Section of Department of Pathology, Sohag University Hospital in the period from March 2014 to April 2016.

Fifty peri and postmenopausal women were included in this study, each patient were subjected to accurate history taking regarding parity, contraceptive use, menstrual history, and duration of marital life and the status of cervix (healthy or unhealthy) by per-vaginal examination of the patients.

The specimens were collected as follows; firstly the speculum was inserted without lubricant. Any mucous, discharge or blood was removed with dry cotton. A wooden spatula was used for sampling ectocervix which is rotated $\mathbf{3 6 0}$ degrees. For sampling endocervix, the brush was rotated only $\mathbf{9 0}$ degrees as the circumferential bristles were in contact with the entire surface the moment the brush was inserted. The samples were applied to the slides which were encoded and immediately fixed in $95 \%$ ethanol and stained by the standard Pap stain. The Bethesda System (2014) was used for cytological interpretation (Nayar and Wilbur, 2015).

The steps of the manual conventional Pap staining are: firstly, the slides were washed in descending concentration of alcohol as follows $96 \%, 80 \%, \mathbf{7 0 \%}$, $\mathbf{5 0 \%}$, and then washed in distilled water. The slides were stained in Harris' haematoxylin solution for $\mathbf{3}$ min, rinsed in weak stream of tap water for 3-5 $\mathrm{min}$. The slides were immersed in ascending concentration of alcohol $50 \%, 70 \%, 80 \%$, and $96 \%$ for dehydration. Slides were stained with Pap OG6 solution $3 \mathrm{~min}$, and washed in $96 \%$ alcohol two times. Slides were stained in Pap solution EA50 for $\mathbf{3}$ min, and then washed in $96 \%$ alcohol twice again. Slides were dehydrated in absolute alcohol for $\mathbf{5} \mathrm{min}$, cleared with xylene for $\mathbf{2}$ minutes then mounted with DPX. Finally, slides were cover slipped and allowed to harden for 20-30 minutes.

\section{Statistical analysis:}

Results were statistically analyzed using Statistical Package for Social Sciences 16 (SPSS 16) for Windows. Chi-Square test was used to evaluate statistical significance of various parameters with $\mathrm{P}$ value less than was 0.05 considered statistically significant. 


\section{Results}

The age of the patients ranged from 38 to $\mathbf{7 0}$ years with a mean of $\mathbf{5 0 . 0 8 \pm \mathbf { 1 0 . 7 3 6 }}$ and median of 49 (Table 1). Twenty nine (58\%) women were premenopausal and 21 $\mathbf{4 2 \%}$ ) were postmenopausal. Bleeding was the main complaint in $\mathbf{9 2 \%}$ patient and the remaining $\mathbf{8 \%}$ complained from vaginal discharge and itching (Table 2).

Thirty nine patients were negative for intraepithelial lesion or malignancy (NILM), eight showed neoplastic changes, and $\mathbf{3}$ samples were insufficient for cytological interpretation.

Two out of the $\mathbf{8}$ cases showed neoplastic lesions were ASCUS, two diagnosed as ASC-H (Fig. 1 a), 3 were HSIL (Fig. 1 b) and one cases had features of SCC (Fig. 1 c, d). Regarding the neoplastic group, by re-evaluation of the $\mathbf{2}$ cases of ASCUS after $\mathbf{6}$ months one case showed normal cytology and the other is diagnosed as HSIL which means that $\mathbf{5 0 \%}$ of ASCUS showed regression. Six out of 39 samples showed only pure atrophy, three showed follicular cervicitis, three had features suggestive of Tichomonas vaginalis infection, one diagnosed as HSV infection, one showed bacterial vaginosis and eleven cases showed nonspecific inflammation.

Non-neoplastic cases included also six cases showed metaplastic changes and eight had normal cytological findings (table $\mathbf{3}$ ).

In the current study, 42/50 samples; 26 premenopausal and the 16 postmenopausal women samples' showed benign cytological findings, whereas the premalignant and malignant findings were found in five postmenopausal and three premenopausal samples (table 4). The relation between the patient's age and their final diagnosis didn't reach the statistical significance $(\mathbf{0 . 2 5 6})$.

Table 1: The cytological finding according to age groups

\begin{tabular}{|l|l|l|}
\hline $\begin{array}{c}\text { Age } \\
\text { Diagnosis }\end{array}$ & $\leq 45$ & $>\mathbf{4 5}$ \\
\hline Normal & $\mathbf{5 ( 1 0 \% )}$ & $\mathbf{3 ( 6 \% )}$ \\
\hline Inadequate & $1(2 \%)$ & $\mathbf{2 ( 4 \% )}$ \\
\hline Non neoplastic lesion & $14(28 \%)$ & $17(34 \%)$ \\
\hline ASCUS & & $\mathbf{2 ( 4 \% )}$ \\
\hline ASC-H & $1(2 \%)$ & $1(2 \%)$ \\
\hline HSIL & $1(2 \%)$ & $\mathbf{2 ( 4 \% )}$ \\
\hline SCC & & $1(2 \%)$ \\
\hline
\end{tabular}

Table 2: The clinical presentations in relation to cytological findings

\begin{tabular}{|c|c|c|c|}
\hline Clinical manifestation & Non neoplastic lesion & Neoplastic lesion & Total \\
\hline Bleeding & $38(76 \%)$ & $8(16 \%)$ & $46(92 \%)$ \\
\hline Itching and vaginal discharge & $4(8 \%)$ & & $4(8 \%)$ \\
\hline
\end{tabular}


Table 3: Classification of the studied cases according to TBS 2014

\begin{tabular}{|c|c|c|c|}
\hline Diagnosis & $\begin{array}{l}\text { Number of } \\
\text { patient }\end{array}$ & $\begin{array}{l}\text { Percentage } \\
(\%)\end{array}$ & Total \\
\hline NILM & 42 & 84 & \\
\hline Atrophy with no other finding & 6 & 12 & \\
\hline Atrophy with follicular cervicitis & 3 & 6 & \\
\hline Atrophy with infection & & & \\
\hline Suggestive of Trichomonas & 3 & 6 & \\
\hline HSV & 1 & 2 & $39(78 \%)$ \\
\hline Bacterial vaginosis & 1 & 2 & \\
\hline Non specific & 11 & 22 & \\
\hline Atrophy with metaplastic changes & 6 & 12 & \\
\hline Normal smear & 8 & 16 & \\
\hline ASCUS & 2 & 4 & \\
\hline ASC-H & 2 & 4 & $8(16 \%)$ \\
\hline HSIL & 3 & 6 & \\
\hline SCC & 1 & 2 & \\
\hline Insufficient smear & 3 & 6 & $3(6 \%)$ \\
\hline
\end{tabular}

Table 4: The relation between the patient's age and neoplasia

\begin{tabular}{|l|l|l|l|}
\hline Cytological findings & $\begin{array}{l}\text { Premenopausal } \\
\text { women }\end{array}$ & $\begin{array}{l}\text { Postmenopausal } \\
\text { women }\end{array}$ & Total \\
\hline Benign & $\mathbf{2 6}(52 \%)$ & $\mathbf{1 6}(32 \%)$ & $\mathbf{4 2}(\mathbf{8 4 \% )})$ \\
\hline $\begin{array}{l}\text { Premalignant and } \\
\text { malignant }\end{array}$ & $\mathbf{3 ( 6 \% )}$ & $\mathbf{5 ( 1 0 \% )}$ & $\mathbf{8 ( 1 6 \% )}$ \\
\hline
\end{tabular}

\section{Discussion}

In our study, we are dealing with epithelial cell abnormality of cervical epithelium in peri and postmenopausal women complaining mainly from bleeding. Fifty patients were included; all of them were of low socioeconomic standard. Thirty one (62\%) of our cases showed benign changes in form of; atrophy $6(\mathbf{1 2 \%})$, atrophy with infection $16(32 \%)$, and atrophy with metaplastic changes 6 (12\%). Premalignant and malignant changes were detected in $8(\mathbf{1 6 \%})$ of them; 2 (4\%) ASCUS, 2 (4\%) ASC-H, $3(6 \%)$ HSIL and $1(2 \%)$ SCC.

The age range of women included in this study started from $\mathbf{3 8}$ to $\mathbf{7 0}$ years; along perimenopausal period to postmenopausal period, so the detected atrophic changes varied from mild to severe changes, associated with few to abundant metaplastic changes according to the patient age.

The prevalence of our neoplastic cases $\mathbf{( 1 6 \% )}$ ) was more than that of
$(5 \%, \mathbf{1 3 . 6 \%})$ in the study of Bal et al., (2012) and of Verma et al., (2014) respectively. This may be due to small number of cases in our study due to that all out-patient were symptomatic and did not come for screening as a routine process. This may give another explanation for the higher percentage of positive cytology in correlation to the reports of the others. In the present study, bleeding is the main symptom $\mathbf{( 9 2 \% )}$ in the studied patients, followed by vaginal discharge and itching $(\mathbf{8 \%})$ of the studied cases. In contrast, Verma et al., (2014) which revealed that the most presenting complaint was vaginal discharge, followed by abdominal pain and post coital bleeding in $\mathbf{5 4 . 4 0 \%}$, $45.60 \%$ and $16.80 \%$ respectively. This may be explained by the fact that in our community the females are less aware with screening importance.

All neoplastic cases in the current study were suffering from bleeding as previously reported by Gupta et al., 
(2013) who found that the common complaint in high grade dysplasia was postmenopausal bleeding.

The study of Kaur et al., (2010) revealed that the predominant causes of postmenopausal bleeding were endometrial pathology as simple hyperplasia without atypia, atypical hyperplasia, endometrial carcinoma, and cervical lesions as endocervical polyps, small number of cervical dysplasia and SCC. This explains why $\mathbf{4 2 \%}$ of our studied cases were negative for cytological finding.

The number of cases inadequate for cytological evaluation in this study 3 $\mathbf{6} \mathbf{6 \%}$ ) was larger than those found in a study done by Bukhari et al., (2012) in which the cases inadequate for cytological evaluation represented only $\mathbf{1 . 8 \%}$. This may be due to sampling and technical errors.

In the present study, two cases $(\mathbf{4 \%})$ were diagnosed as ASCUS which showed mild atypia that did not match features of atypia of LSIL or HSIL, and the patients were above $\mathbf{4 5}$ years of age. The percentage of cases showing features of ASCUS in the current study was much lower than that $\mathbf{( 9 . 8 \% )}$ reported in the Pap smears in a study of Bukhari et al., (2012). This difference may be due to the small number of cases in our study.

Rinku et al., (2007) reported that on repeating Pap smear in cases previously diagnosed as ASCUS, 45.2\% of cases returned to normal and $\mathbf{3 0 . 2 \%}$ of cases showed only benign cellular changes; which means that $\mathbf{7 5 . 4 \%}$ of cases were regressed, this go on with our result as $\mathbf{5 0 \%}$ of ASCUS showed regression. Williams et al., (1997) reported that between $10 \%$ and $\mathbf{3 0 \%}$ of histological LSIL or HSIL were diagnosed when women with ASCUS were followed up. This clarifies the importance of following the criteria of Bethesda (2014) in the diagnosis of ASCUS due to its importance in the patient's management.

McGrath, (2002), concluded that ASCUS in postmenopausal women was less likely to be associated with SIL than in premenopausal women due to the similarities between the atrophic and the dysplastic cells. This conclusion points to the significance of our study that tried to identify similar pitfalls.

In the current study two cases $(4 \%)$ were diagnosed as ASC-H as there was higher atypia than in ASCUS but did not match all features of HSIL. In diagnosing ASC-H, we strictly apply the features of recent modification of The Bethesda system (2014) to ensure high sensitivity in the diagnosis, in contrast, Chivukula and Shidham, (2006) found challenge in the diagnosis ASC-H cases. This explained by that they may use the old version of The Bethesda system (2001). Howell et al., (2009) found that a higher percentage $\mathbf{2 0 \%}$ ) of smears diagnosed as ASC-H showed CIN-II lesions on follow up than did smears diagnosed as ASCUS (5\%), so careful diagnosis of ASC-H cases help in early management of the patients.

In our study, we strictly examined the cases showing features of HSIL and applied the features of The Bethesda system (2014) to avoid missing positive cases. Three cases $(6 \%)$ in our study were diagnosed as HSIL in which the cells were similar in size to parabasal cells and showed nuclear atypia but without diathesis. Saad et al., (2006) reported that the diagnosis of HSIL in postmenopausal women is difficult as the atrophic cells may appear as single cells rather than sheets and the nucleus may be hyperchromatic with high N/C ratio.

Ahlgren et al., (1975) reported that the recognition of HSIL in old women has important clinical significance as HSIL is less likely to regress 
spontaneously than other earlier lesions as ASCUS and ASC-H. This implies the significance of our result.

In our study one case (2\%) was diagnosed as squamous cell carcinoma of cervix uteri due to the presence of pleomorphic cells, tadpole cell and fiber cells, tumor diathesis and keratinization and nuclear chromatin abnormalities, presence of prominent nucleoli. Clark and Dawson, (2002) demonstrate that in cases of invasive squamous cell carcinoma, the presence of a tumor diathesis, coexistent dysplasia, and/or keratinization are useful criteria for diagnosis of squamous cell carcinoma using Thin Prep method.

These finding were the similar to our findings despite we use conventional Pap smear. Also invasive squamous cell carcinoma in conventional Pap smear showed high cellularity in comparison to the study of Clark and Dawson, (2002) in which they recognize low cellularity in association with invasive squamous cell carcinoma.

Leung et al., (1994) reported that the presence of the diathesis with dysplasia in $\mathbf{8 . 3 \%}$ of $\mathbf{4 8}$ cases of CIN III. In our study we apply the strict criteria according to recent modification of Bethesda system (2014). The only squamous cell carcinoma case was diagnosed in postmenopausal woman complaint of abnormal uterine bleeding which was similar to the finding of Gupta et al., (2013) who demonstrated that the frequency of cervical cancer is higher in women with postmenopausal bleeding.

One of the significant discrepancies between our results and previous published data is the absence of diagnosis low grade squamous intraepithelial lesions (LSIL), which may be due to sampling error, small number of the studied cases, low incidence of HPV infection and the old age of the patients. The age incidence of low grade lesions was in the reproductive age with a peak in the 3539 year age range as reported by Banik et al., (2011). Abdel-Hadi et al., (2015) reported that LSIL constituted $\mathbf{0 . 0 9 \%}$ of screened women in a study included 6173 women of different ages which support our findings.

Our results don't reveal any glandular lesions, and this may be due to small number of studied cases, and technical errors. Pak et al., (2007) reported that the rate of false negative Pap smears is high in adenocarcinoma. In a study done by Kalir et al., (2005) it has been shown that cervical adenocarcinoma may arise above the level of the TZ or growing beneath the surface sparing the surface mucosa. It becomes clear that the diagnosis of cervical adenocarcinoma is difficult and consistent with our results.

The age range of the studied cases was 38-70, and the mean age was 50.08 years. The small sample size of the studied patients did not allow adequate number of cases in each age group, so the relation between the patients' age and their final diagnosis didn't reach the statistical significance (0.256). In comparison Bal et al., (2012) reported that the mean age of patient with LSIL was $\mathbf{3 2 . 3}$ years, and those with HSIL and invasive carcinoma were $\mathbf{4 0 . 5}$ years and $\mathbf{5 7}$ years, respectively.

\section{Conclusion}

This study highlight the importance of using cervical smears for symptomatic and non-symptomatic female for early detection of cervical carcinoma and its precursors as an easy, costless, accessible, and reliable manner in the Outpatient Clinic of 
Gynecology and Obstetrics Department also clarify the importance of using the Bethesda system (2014) for each sample.

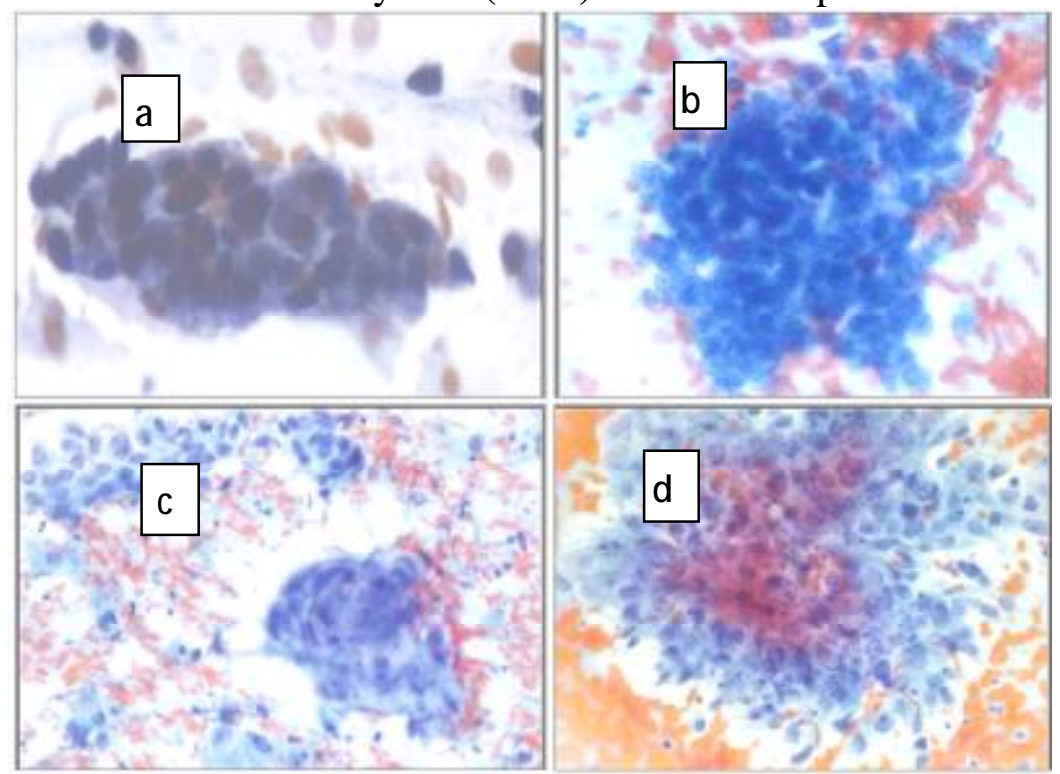

Fig 1: (a) ASC-H (Pap, x400); (b) HSIL (Pap, x400); (c) SCC with cell nest formation (Pap, x400); (d) SCC with keratinization (Pap, x400).

\section{References}

1. Abdel-Hadi M, Khalaf A, Aboulkassem H, Naeem N, Abdel Baqy M, Sallam H (2015). Cervical intraepithelial lesions in females attending Women's Health Clinics in Alexandria, Egypt. CytoJournal; 12:13.

2. Ahlgren M, Ingemarsson I, Lindberg L, Nordqvist M, Mordqvist S (1975). Conization as treatment of carcinoma in situ of the uterine cervix. Obstet Gynecol; 46:135-140.

3. Arbyn M, Anttila A, Jordan J, Ronco G, Schenck U, Segnan N, Wiener H, Herbert A, von Karsa L (2010). "European Guidelines for Quality Assurance in Cervical Cancer Screening. Second Edition Summary Document". Annals of Oncology; 21: 448-458.

4. Bal MS, Goyal R, Suri AK, Mohi MK (2012). Detection of abnormal cervical cytology in Papanicolaou smears. J Cytol; 29: 45-47.

5. Banik U, Bhattacharjee $P$, Ahamad S.U, Rahman Z (2011). Pattern of epithelial cell abnormality in Pap smear: A clinic-pathological and demographic correlation. Cytojournal; 8: 8.

6. Bukhari MH, Saba K, Qamar S, Majeed MM, Niazi S, Naeem S (2012). Clinico-pathological importance of Papanicolaou smears for the diagnosis of premalignant and malignant lesions of the cervix. $\mathbf{J}$ Cytol; 29: 20-25.

7. Chivukula M. and Shidham V.B (2006). ASC-H in Pap test definitive categorization of cytomorphological spectrum. CytoJournal; 3: 14.

8. Clark S.B. and Dawson A.E. (2002). Invasive SCC in Thin Prep Specimens: Diagnostic Clues in the Cellular Pattern. Diagn. Cytopathol; 26: 1-4.

9. Collaço L.M and Zardo L (2008). Cytological Screening Programs. In: Comprehensive Cyopathology, third edition, Elsevier, China, p. 47-57.

10. DeMay M. (2007). Practical principles of cytopathology. Revised edition. Chicago, IL: American Society for Clinical Pathology Press. 
11. Ferlay J, Soerjomataram I, Ervik M, et al. GLOBOCAN (2012), Cancer Incidence and Mortality Worldwide: IARC Cancer Base No. 11. Lyon, France: International Agency for Research on Cancer; 2013. Available from: http://globocan.iarc.fr(link is external), accessed December2013.

12. Gupta K, Malik NP, Sharma VK, Verma N, Gupta A (2013). Prevalence of cervical dysplasia in western Uttar Pradesh. J Cytol; 30: 257-262.

13. Howell L.P, Gurusinghe S, Tabnak F (2009). Impact of ASC-H terminology on the detection of HSILs in medically underserved California women. Diagn. Cytopathol; 37: 103-110.

14. ICO Information Centre on HPV and Cancer (2016). Egypt: Human Papillomavirus and Related Cancers, Fact Sheet (October 7, 2016).http://www.hpvcentre.net/sta tistics/reports/EGY_FS.pdf.

15. Kalir $\mathrm{T}$, Simsir A, Demopoulos HB, Demopoulos RI (2005). Obstacles to the early detection of endocervical adenocarcinoma. Int $\mathbf{J}$ Gynecol Pathol; 24: 399-403.

16. Kaur J, Dey P, Saha S.C, Rajwanshi A, (2010). Cervical cytology in patients with postmenopausal bleeding. Diagn. Cytopathol; 38: 496-498.

17. Leung KM, Chan WY, Hui PK (1994). Invasive SCC and cervical intra-epithelial neoplasia III of the uterine cervix. Morphologic differences other than stromal invasion. Am J Clin Pathol; 101: 508-513.

18. McGrath CM (2002). ASCUS in Papanicolaou smears: problems, controversies, and potential future directions. Am J Clin Pathol; 11: 62-75.

19. Moss SF and Blaser MJ (2005). Mechanisms of Disease: Inflammation and origins of cancer. Nat Clin Pract Oncol; 2: 907.

20. Nayar R, Wilbur DC (2015). The Bethesda System for Reporting Cervical Cytology: Definitions, Criteria, and Explanatory Notes, ed 3. New York, Springer.

21. Pak S.C, Martens M, Bekkers R, Crandon A.J. (2007). Pap smear screening history of women with SCC and adenocarcinoma of the cervix. Australian and New Zealand Journal of Obstetrics and Gynaecology; 47: 504-507.

22. Rinku S, Vijayalakshmi B, Anupama J, Poonam C (2007). A prospective study of 86 cases of ASCUS over two years. J Obstet Gynecol India; 57:73.

23. Saad R.S., Kanbour-Shakir A, Lu E, Modery $\mathbf{J}$ and Kanbour A (2006). Cyto-morphological Analysis and Histological Correlation of HSIL in Postmenopausal Women. Diagn. Cytopathol; 34: 467-471.

24. Verma I, Jain V, Kaur T (2014). Bethesda System for Cervical Cytology in Unhealthy Cervix. Jcdr; 8: 26-30.

25. Williams ML, Rimm DL, Pedigo MA et al., (1997). ASCUS: correlative histological and follow up studies from an academic medical center. Diagn Cytopathol; 16: 1-7. 